\title{
An Exergame Concept for Improving Balance in Elderly People
}

Nawaz, Ather; Waerstad, Mathilde; Omholt, Kine; Helbostad, Jorunn L.; Vereijken, Beatrix; Skjæret, Nina; Kristiansen, Lill

Document Version

Accepted author manuscript

Published in:

ICTs for Improving Patients Rehabilitation Research Techniques

DOI:

10.1007/978-3-662-48645-0 6

Publication date:

2015

License

Unspecified

Citation for published version (APA):

Nawaz, A., Waerstad, M., Omholt, K., Helbostad, J. L., Vereijken, B., Skjæret, N., \& Kristiansen, L. (2015). An

Exergame Concept for Improving Balance in Elderly People. In H. M. Fardoun, V. M. R. Penichet, \& D. M. Alghazzawi (Eds.), ICTs for Improving Patients Rehabilitation Research Techniques: Second International Workshop, REHAB 2014, Oldenburg, Germany, May 20-23, 2014, Revised Selected Papers (pp. 55-67). Springer. Communications in Computer and Information Science Vol. 515 https://doi.org/10.1007/978-3-66248645-0_6

Link to publication in CBS Research Portal

\section{General rights}

Copyright and moral rights for the publications made accessible in the public portal are retained by the authors and/or other copyright owners and it is a condition of accessing publications that users recognise and abide by the legal requirements associated with these rights.

Take down policy

If you believe that this document breaches copyright please contact us (research.lib@cbs.dk) providing details, and we will remove access to the work immediately and investigate your claim. 


\title{
An Exergame Concept for Improving Balance in Elderly People
}

\author{
Ather Nawaz ${ }^{1}$, Mathilde Waerstad ${ }^{2}$, Kine Omholt $^{2}$, Jorunn L. Helbostad $^{1}$, Beatrix Vereijken ${ }^{1}$, \\ Nina Skjæret ${ }^{1}$ and Lill Kristiansen ${ }^{2}$ \\ ${ }^{1}$ Department of Neuroscience, ${ }^{2}$ Department of Telematics \\ Norwegian University of Science and Technology (NTNU), Norway \\ ${ }^{1}$ ather.nawaz, jorunn.helbostad, nina.skjaret, beatrix.vereijken\}@ntnu.no \\ ${ }^{2}$ lillk@item.ntnu.no, ${ }^{2}\{$ mathildewaerstad, kine.omholt\}@gmail.com
}

\begin{abstract}
Video exercise games (exergames) are becoming increasingly popular among elderly people. Many elderly experience reduced balance and muscle strength which make them at increased risk of falling. Muscle strength and balance training are the key components for preventing function decline and falls at old age. Exergames that are to be used among elderly users should be specifically designed for this group of people. This study aims to design and evaluate an exergame concept developed to fit the need and preferences of elderly users. First, seven elderly people tested three commercially available exergames. Feedback from focus group interviews revealed that the design of the existing exergames should be simplified and more closely related to activities that can be associated with older people's daily life. Based on the feedback a new exergame concept "in nature" was designed. The new exergame concept had a simple design, and included balance and muscle strengthening exercises related to real life activities. In the results of the workshop, the study provides eight design recommendations for exergame design for seniors.
\end{abstract}

Keywords: Exergames, Design, Seniors, Balance, Falls, Elderly

\section{Introduction}

The use of games for exercise is generally called exergames. The game industry mainly develops these games for a wider audience such as children and adolescents for the purpose of entertainment. The game industry is growing $9.1 \%$ annually to $\$ 48.9$ in 2011 and \$66 billion in 2012, making it the fastest-growing component of the international media. Due to business goals, the game industry is mainly focusing on covering a large population without specific focus on the requirements of senior citizens.

However, the world's population is "greying", with the proportion of the world's population aged 60 and older set to double to more than $22 \%$ of the overall population by 2050 [1]. The ageing process includes decline in visual and auditory systems, as well as slowing down in movements [2]. Due to the increasing number of elderly 
people, movement impairments and the lack of physical activity among this age group will likely become one of the major societal challenges in the next decades.

One in three persons over the age of 65 , and half of those over the age of 80 , fall at least once per year. International guidelines on physical activity in older people highlight the need for balance and muscle strength training in order to prevent loss of physical function and falls [3].

Exergames have the potential to motivate senior citizens to be physically active. Exergames also have the potential to improve health-related issues among senior citizens, such as decreasing depression [4], and increasing physical function in general [5] and balance in particular [6]. However game technologies need to be designed and developed based on the older persons' needs and preferences. Furthermore, in order to prevent physical decline and falls, exergames developed for older people should also aim to work on balance control and muscle strength.

\subsection{Relevant work on design of exergames}

A number of studies have focused on psychological effects of exergames $[4,7,8]$. However, not many studies have focused on designing senior-centered exergames for physical fitness in general and balance training in particular. To meet individual variability in level of physical function among older people, games should provide different difficulty levels so that seniors can adjust according to their comfort and needs. Gerling et al. [9] outlined four general points that are important for designing exergames for senior citizens: The possibility to 1) play both sitting and standing, 2) avoid too extensive and sudden movements, 3) adjust difficulty level and device sensitivity, and 4) simple interaction mechanisms and feedback in the gameplay. Furthermore, Jongman [10] expressed that design of an exergame for balance training should accommodate weight shifts during movements. A recent study [11] focused on the importance of assessing user experience of seniors when exergaming for balance training. The study finds that healthy seniors liked exergame that was specifically developed for seniors.

Seniors have different preferences, interests and taste of games that might not be the same as in a young population. Loneliness is a challenge among many older people, and reduced physical function makes it difficult to leave the house on their own. Therefore, exergames can offer an opportunity to exercise at home while socializing with others at distance through the gameplay [12]. A recent study [13] linked the movement elements in commercially available exergames with the game elements in each game and concluded that the interface should provide some kind of representation of the players' movements on the screen. However, a fully animated 3D representation is not necessary to achieve the required movements in the player's gaming behavior [13].

The current paper evaluates existing off-the-shelf exergames and, based on feedback from the elderly players, presents a new exergame concept for elderly people for improving balance. The aim of this study is to design a simple concept of an exer- 
game for elderly people using natural tasks that provide an opportunity to train aspects of balance and muscle strength. We conducted two workshops to evaluate previous off-the-shelf exergames and present a new exergame concept. On the basis of the results, this study highlights recommendations for designing exergames for seniors.

\section{Method}

In the context of exergames for seniors, the needs of seniors should be assessed through user-centered design process to make effective exergames for seniors [14]. We employed a user-centered design (UCD) method for designing the exergame [15].

We conducted two workshops with elderly users. The workshops were conducted at a seniors community centre that was familiar to the senior citizens. In the fist workshop the elderly users played three off-the-shelf exergames. After having played the offthe-shelf games they gave their feedback for these existing exergames and provided inputs for new game concepts. The requirements for a new game concept were made based on this feedback of elderly users and inputs for new game concept. Then, a prototype of a new game was designed. The same elderly users were invited to a second workshop aimed at evaluating the new exergame concept.

\subsection{Participants}

We recruited elderly people from a voluntary organization "Seniornett" or senior network. Seniornett is working with elderly citizens to become active users of ICT and internet. Seven elderly citizens participated in the first workshop and five elderly citizens participated in the second workshop. The average age of the participants was $70.6(\mathrm{SD} \pm 7.9)$ years. All participants had their own computer and were familiar with using smartphones, but they had no prior experience with video game technologies.

Five out of seven participants used their computer several times a week. The senior citizens generally used computer for E-banking, email and news. Most of the senior citizens found social aspects of exercising important while four out of seven said that they would like to share information with family and friends through social media. Six out of seven participants said that they were physically active in everyday life and performed regular exercise in classes. Factors motivating them for performing exercise include: being in activity, socializing, achieving a good mood, and maintaining good health.

\section{Workshop 1: Testing Off-the-shelf Exergames}

The first workshop consisted of a gameplay section followed by a focus group where participants discussed their experience with the off-the-shelf exergames, their thoughts about the exergames and the technology, and their requirements for a new exergame. 


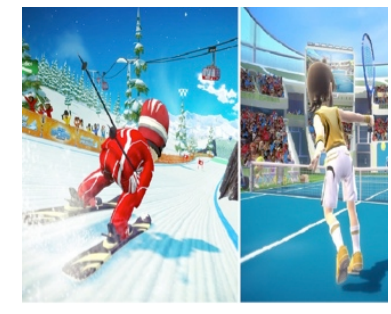

a) Skiing and tennis in Kinect sports

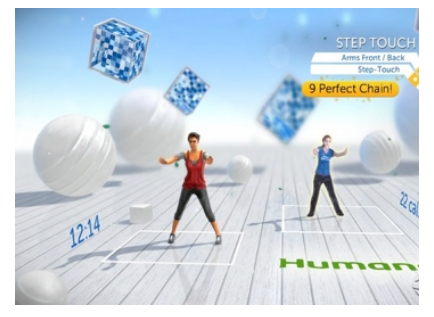

b) YourShape:Fitness Evolved

Fig. 1. The three exergames in workshop 1

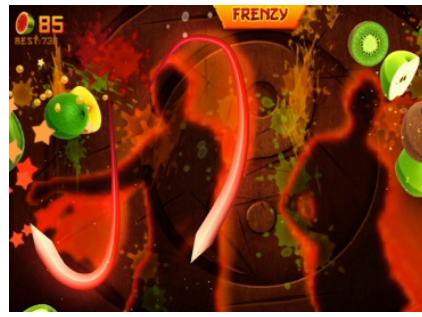

c) Fruit ninja

The three off-the-shelf exergames used in the first workshop were "Kinect Sports: Season Two", "YourShape:Fitness Evolved", and "Fruit Ninja". Kinect Sports consists of six sports. We chose Tennis and Skiing because these games stimulate movement and balance activity in a fun and motivating way. YourShape is a fitness game that includes mini games. In the game pack YourShape, we chose "Aging with grace". We chose "aging with grace" because it was specifically designed for elderly.

Fruit Ninja is a game where players use their arms like a ninja to slice fruit that is thrown up into the air. This game was chosen on the basis of fun and balance requirements of the movements.

\subsection{Procedure of Workshop 1}

The first workshop was held over a period of two days. All seven seniors were present for introduction of the study on the first day of the workshop. However four seniors played exergames on the first day and provided their feedback. Three seniors played games on the second day of the workshop and provided their feedback. The workshop consisted of a gameplay section followed by a focus group. Before playing the three exergames, participants were introduced to the technology and how to interact with it. The participants in each group first played the games individually, and then competed against one another using a multi-players setting. Each participant played three games for a total of approximately 25 minutes. After gameplay, the participants provided feedback on their experience with the gameplay and the technology for all three exergames in a focus group interview 


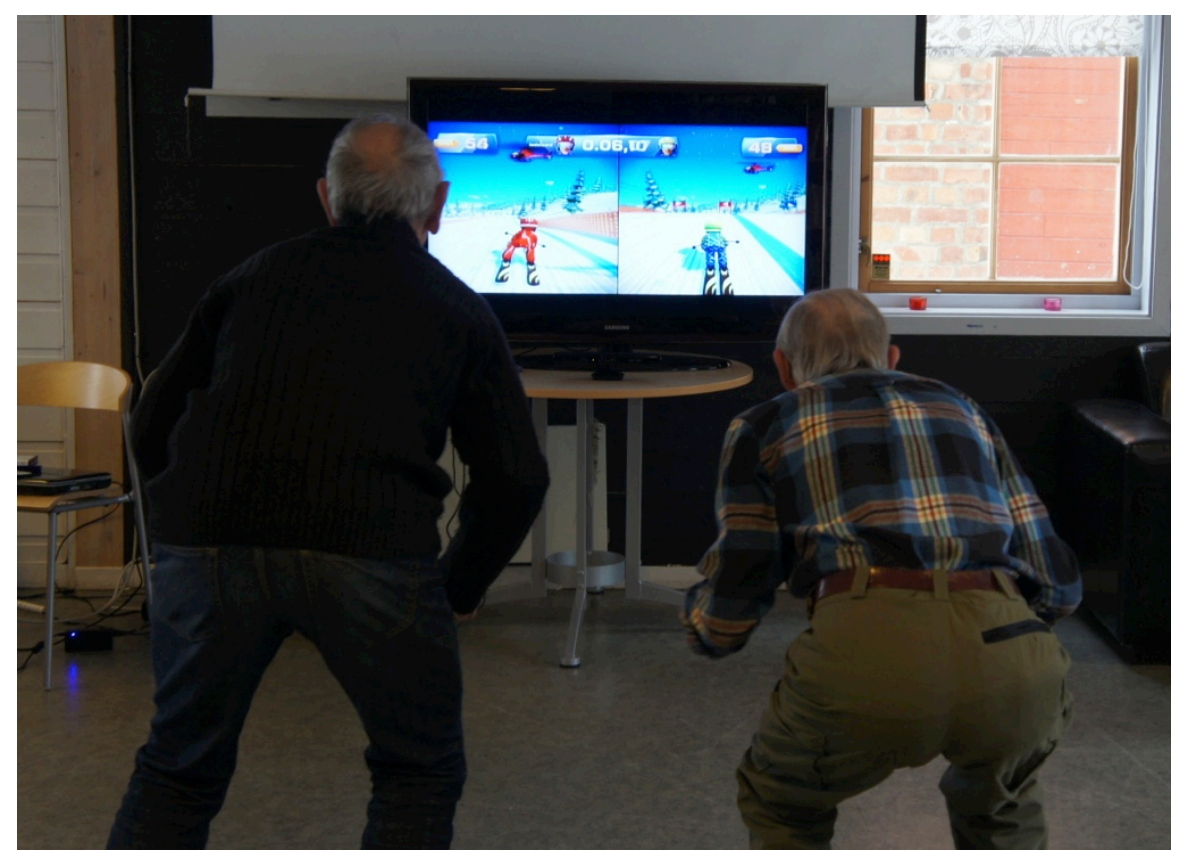

Fig. 2. Two participants compete in the skiing game in Kinect Sports

Two video cameras were used from different angles for recording. The first camera was placed in front of the TV and camera was used to capture facial expressions and movements with the game. The second camera was placed in a corner of the room to capture the overall environment of the room.

After playing game focus session was conducted with participants where participants discussed their experience with the off-the-shelf exergames, their thoughts about the exergames and the technology, and their requirements for a new exergame During the focus group, participants were asked about the challenges they faced while playing the exergames The feedback of the participants was transcribed and coded. A set of themes was derived from the feedback of participants in workshop

\subsection{Findings of Workshop 1}

The participants expressed that they liked Tennis and Skiing because they could relate it to previous real life experiences with skiing and playing tennis. They also liked it because these two games were physically more challenging, fun and entertaining than the other two games. Skiing was the game that engaged the players most while playing the game. Our interpretation is that seniors had higher level of engagement because Skiing is a popular sports in the area. Following are general points expressed by the seniors in the focus group discussion.

Information display: There was a general opinion among the seniors that too many things were presented at the screen during the game-plays of all games. For the Fruit 
Ninja game, one of the participants stated, "there are too many elements on the screen. Where should you look"? The participants stated that too many things were going on at the same time and that it was hard to do move hand simultaneously. The participants expressed that the interface was too complex in all games. One of the participants said: "the menu was extremely difficult", while another stated while trying to give input through hand gestures, "this is worse than working with the mouse on the computer". The participants wanted to see less information and elements on the screen at the same time.

Recommendation 1: The interface should be simple with minimal and relevant information only.

Outcome of the game: Participants wanted information regarding the specific effect and outcome of the exercises. They wanted to know why to do the different tasks and what kind of training benefits the games could give them beyond entertainment. The participants also wanted to know if they performed the movements correctly or not. One of the participants stated, "It [the game] needs to be softer and [there should be] more instructive introduction into the game's rules and objectives". From a design perspective, the purpose and benefits of doing the exercises should be clearly described.

Recommendation 2: The primary focus within game play experience should be on movement quality without too much distraction.

Recommendation 3: The exergame should provide a clear indication of expected results and benefits of what can be achieved by playing the game.

Progress and learning: The participants expressed that they wanted a simple way to display progress and learning in their game-play. One of the participants stated, "It is all about the experience of mastery, which is essential. The older you get, the more important it gets to progress". Another participant suggested different levels of tasks in the game and stated, eventually, "when you get better and manage to keep track of things, you can add more elements to the game. A lot of what happens in these games is not relevant". The other participant expressed that progress and learning in the exergame was not same as she experience in aerobic class, "we used to attend an aerobic class where they practiced exercises slowly before they could do it fast. I do not feel it [progress] the same way". Another participant stated that she did not want to get forced into something she did not want to do, and that she wanted to be able to choose 
which difficulty level to play in. "I am thinking that I do not want to get forced into something that is hard, that I do not master because then I get mad". One of the participant stated that she would like to see puzzle in the game.

Recommendation 4: The elderly users should be able to choose and add difficulty elements in the game for confidence and better progress.

Music: The participants did not like the music and background noise in the three game systems. Cheering, loud music, encouraging comments and fans were perceived as noisy and annoying by some of them. One of the participants stated, "I think everything about that [music] was too much". The participants rather wanted old music of their time, with less noise. Another participant stated, "You get sensitive to sound, you want to be active but without too much noise".

Recommendation 5: The game should provide age-appropriate music for elderly users, and the music should fit the aim of the game or the movements performed.

Game suggestions: In the feedback session in workshop 1, participants suggested that real-life activities for game design. These real-life activities includes wood chopping, sports, swimming, rowing, picking apples, biathlon, interval exercises, dance, puzzle games, and a walk in nature. In addition, it was mentioned that if the aim of the game was exercising, they wanted a full workout session including warm-up exercise, cool-down and stretching.

Recommendation 6: The game story should be close to real-life activities of seniors.

\section{$4 \quad$ Prototyping the New Exergame}

Based on the feedback from workshop 1, a horizontal prototype exergame concept was developed. A horizontal prototype provides a broad view of the system, focusing on user interaction more than on lower-level system functionality. A horizontal prototype reduces the level of functionality in prototype of the system. We made a horizontal prototype because it was a quick way of designing an interface and get feedback before moving to the next phase for development of an exergame. As shown in figure 3 , the prototype focused on visual and sensory experiences of exergame design [16]. 


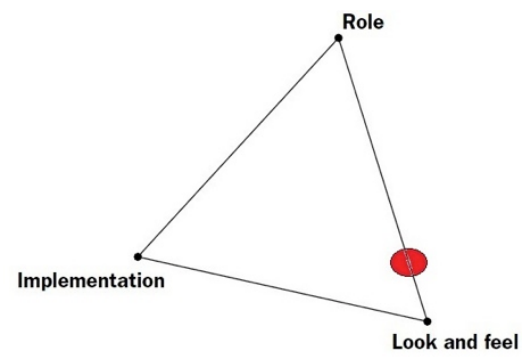

Fig. 3. Implementation of prototype in prototype triangle

The two flow charts shown in figure 4 show how the game-story can be organized through two scenarios.

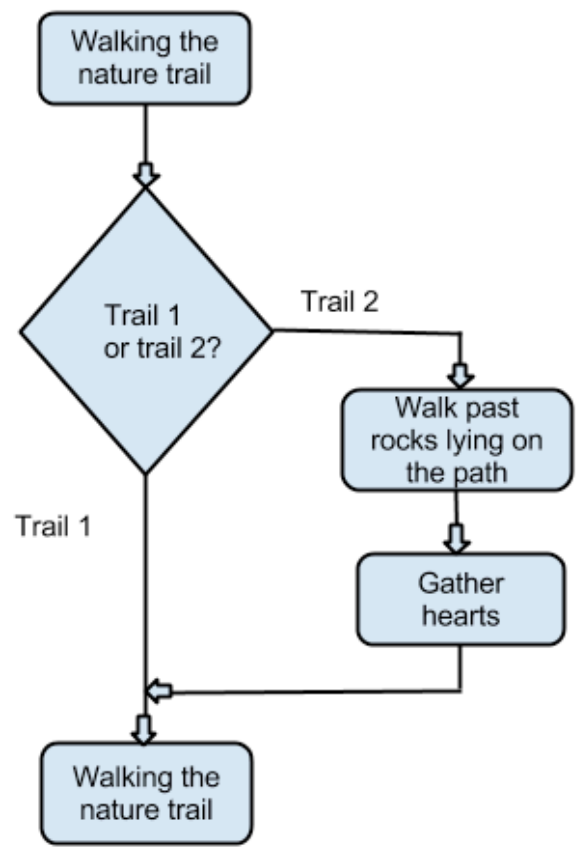

(a)

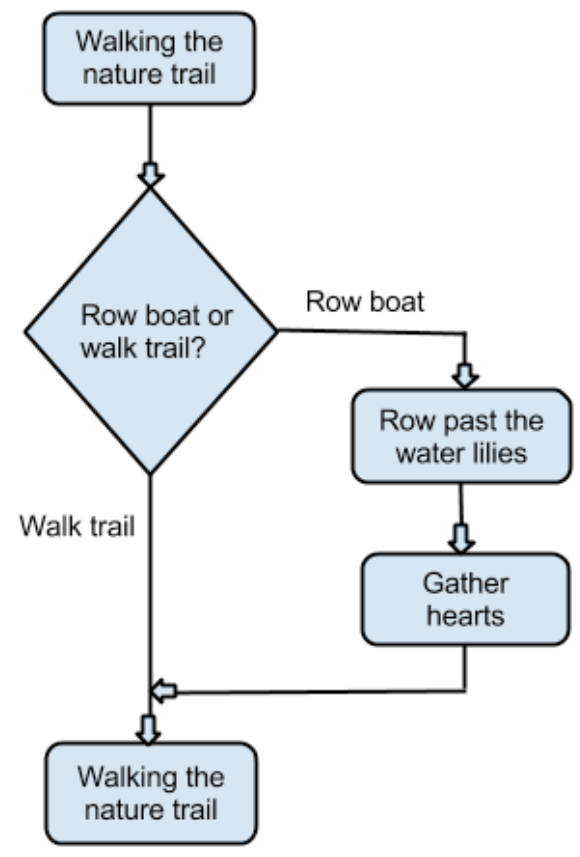

(b)

Fig. 4. Flow charts of two ways of "branching" in the game (a) The player can choose between two different trails and (b) The player can choose between walking the trail or rowing a boat over to the other side of a lake

In Figure 4 (a), the player can choose to walk trail 1 without obstacles and hearts. This trail can be done just by walking. In trail 2 , on the other hand, there are obstacles that need to be avoided, and hearts to gather. This trail will take some more time, but at the same time, exercises more of the body, which might result in a better score. In 
Figure 4 (b) the player can choose to walk the trail without obstacles and hearts, or choose to row a boat over to the other side of a lake. The second scenario provides the elements such as water lilies that should be avoided, and hearts that are be gathered. After finishing the chosen trail, the player will end up on the same trail again. The new level can be added in the game by changing the tail and speed of the game.

\subsection{Interface of New Exergame}

Figure 5 provides an example of an exergame interface that was prototyped for seniors to fit their needs and preference. The exergame contains different levels of difficulties. The player completes the easiest level first, and then proceeds to the next level. This is done for the player to be able to learn the game sufficiently before progressing to a more advanced level. The player could also play the game in collaboration with other players or compete against other players.

In the new concept, the seniors can choose exercises according to different body muscles and choose an exercise depending upon their own preference or the recommendation from a physiotherapist. This would provide elderly users with a clear objective and benefits of exercising. The design of the exergames reflects the goals of training muscle strength and/or balance For example, the goal of one of the exergames concepts is to pick as many ripe apples from a tree as possible within a given time. This activity requires players to stretch their body to reach for ripe apples (balance) and put them in a basket on the ground by performing deep squats (muscle strength). New, unripe apples appear on the tree and turn red when they are ripe. If the apple hangs on the tree too long, it rots and falls off the tree. The player gets points from picking red apples, and loses points both for picking unripe apples and from letting an apple rot.
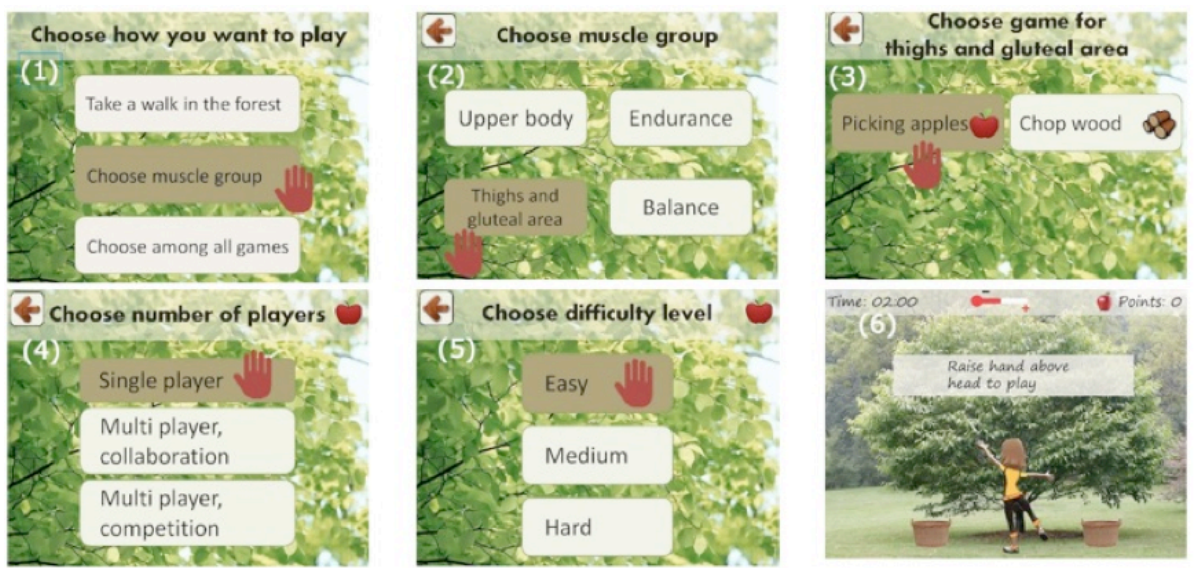

Fig. 5. The menu focuses on exercising different muscle groups

As shown in figure 5, the prototype provides a simple interface with limited information, which is easy to understand for elderly users and helps them to focus more on 
the actual activity rather than confusing users with rich information displayed at different places on the screen.

Figure 6 presents the interface of different obstacles in the nature trail, which also challenges players' muscle strength and balance. A set of obstacles were added, necessitating the following actions: (a) jump from rock to rock to get over the river, (b) walk over the log lying across the path, (c) duck under the branch hanging over the path, (d) get over the lake by rowing the boat, (e) balance on the log to get over the river, (f) walk on the rocks lying on the path. As the seniors expressed the idea of doing a quiz in exercise, the design also included quizzes in the nature trail so participants could answer questions while maintaining their balance.
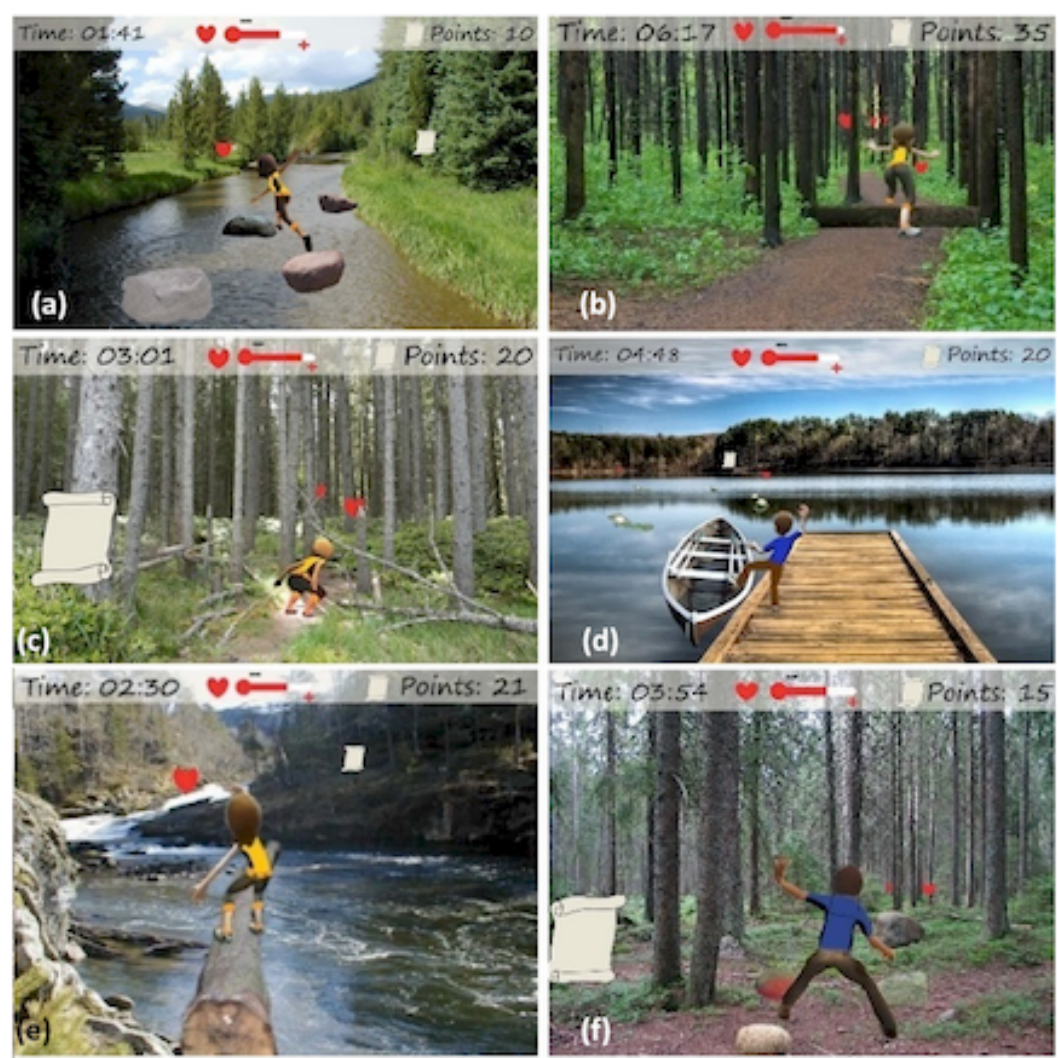

Fig. 6. Obstacles in the nature trail

\section{Workshop 2 : Presenting the New Exergame Concept}

A second workshop was conducted at the same location as workshop 1 to get the feedback of senior citizens regarding the new exergame prototype. All participants from workshop 1 were invited to participate in the second workshop. The participants of the workshop were presented with the summary of the issues that were identified in 
the first workshop and the interface of the new game "Out in Nature". A computer and a projector were used to show the concept of the new game. The seniors were also provided with the paper prototypes of the interface.

\section{$5.1 \quad$ Findings of Workshop 2}

In the second workshop, the participants did not have many inputs and feedbacks. The participants of the second workshop generally liked that the exergame design of "out in nature" had a familiar environment. However, some of the seniors were concerned that including quizzes in the nature trail would take the focus away from the physical tasks to cognitive tasks. One senior stated, "Answering the questions in the quiz will become some kind of test on how good you are, and that is not how I have understood the point of these games".

Recommendation 7: The exergame concept must describe if the outcome of the game is a physical challenge, a cognitive challenge or both.

They liked that there were different difficulty levels in the game and another user stated, "I think that it is an advantage that everyone starts at the easy level, and the more confident you get the harder it gets. I think that is a good way to be controlled". However, the participants wished clearer description of what was required for different difficulty levels. Senior users liked the idea of having a nature trail to play an exergame, which would be entertaining and fruitful and at the same time increase their physical activity level. The users expressed that the design of the new game was simple to understand as it only showed limited information.

Recommendation 8: The exergame concept must make it clear what kinds of movements are required at different difficulty levels.

For music, the seniors were curious about what kind of music the games would get, "I am wondering, about the atmosphere and environment, when I am balancing there [on the $\log$ ], will I hear the sound of water"?

Regarding methodological considerations of the study, it was challenging to present an interactive exergame with a paper prototype to such an inexperienced group, and the participants had little feedback and comments on the game design. This was one of the reasons that seniors did not provide many inputs on the new design. Future prototype should focus on developing more interactive prototypes to increase the users understanding of the game. 


\section{Conclusion}

This study evaluates off-the-shelf exergame, designs new game concept, and evaluates exergame concept that fits the need and preferences of elderly users. The evaluation of three off-the-shelf exergames and presentation of a new exergame provided several important lessons for the design of exergames for senior citizens. First of all, it is important to show only limited information on the screen. Seniors prefer to focus on a single activity in the game rather than doing multiple activities such as physical activity and a quiz at the same time. Secondly, the exergame should provide the objective of the game at the start so that seniors are aware of the required activities and their potential effect. Thirdly, special focus should be given to progress and learning. Initial gameplay should be slower with subsequent progression in speed and difficulty as the senior advances. Lastly, age-appropriate music should be provided in accordance with seniors' choice. These are important aspects to take into consideration for exergames to be a relevant tool for senior citizens to train their physical function and prevent falls.

This study demonstrates the importance of designing exergames for seniors with simplified interfaces. The study provides a prototype that gives an example of how such a simple interface can be developed which can focus on different ways to train balance and strength in seniors. Designing the game with different exercises would allow seniors to train different muscle groups and enjoy the game at the same time.

\section{$7 \quad$ Acknowledgements}

The research leading to these results has received funding from the European Union Seventh Framework Programme (FP7/2007-2013) under grant agreement FARSEEING $\mathrm{n}^{\circ}$ 288940. FARSEEING aims to promote better prediction, identification and prevention of falls with focus on ICT devices. We thank the older seniors from Seniornett for taking part in the project.

\section{References}

1 Factbox on video game industry, Retreived November 14, 2013 from http://in.reuters.com/article/2013/06/10/gameshow-e-idINDEE9590DW20130610,

2 Billis, A. S., Konstantinidis, E. I., Mouzakidis, C., Tsolaki, M. N., Pappas, C., \& Bamidis, P.D.: A game-like interface for training seniors' dynamic balance and coordination. In Proceedings of IFMBE, Volume 29, pp 691-694 Springer,Heidelberg (2010)

3 Gillespie, L.D., Robertson, MC., Gillespie, Sherrington, C., Gates, S., Clemson, L.M., Lamb, S.E.: Interventions for preventing falls in older people living in the community. Cochrane Database Syst Rev, 9(11), (2012)

4 Rosenberg, D., Depp, C. A., Vahia, I. V., Reichstadt, J., Palmer, B. W., Kerr, J., Jeste, D. V.: Exergames for subsyndromal depression in older adults: A pilot study of a novel intervention. American Journal of Geriatric Psychiatry, 18(3), 221-226, (2010) 
5 Jung, Y., Li, K. J., Janissa, N. S., Gladys, W. L. C., \& Lee, K. M.: Games for a better life: effects of playing Wii games on the well-being of seniors in a long-term care facility, in Proceedings of the Sixth Australasian Conference on Interactive Entertainment, ACM, (2009)

6 Schoene, D., Lord, S. R., Delbaere, K., Severino, C., Davies, T. A., \& Smith, S.T.: A Randomized Controlled Pilot Study of Home-Based Step Training in Older People Using Videogame Technology. PLoS ONE, 8(3), (2013)

7 Maillot, P., Perrot, A., \& Hartley, A.: Effects of interactive physical-activity video-game training on physical and cognitive function in older adults.Psychology and aging, 27(3), $589,(2012)$

8 Anderson-Hanley, C., Arciero, P. J., Brickman, A. M., Nimon, J. P., Okuma, N., Westen, S. C., \& Zimmerman, E. A.: Exergaming and older adult cognition: a cluster randomized clinical trial. American journal of preventive medicine, 42(2), 109-119, (2012)

9 Gerling, K. M., Schild, J., \& Masuch, M.: Exergame design for elderly users: The case study of SilverBalance, in Proceedings of the 7th International Conference on Advances in Computer Entertainment Technology. Taipei, Taiwan. p. 66-69, ACM, (2010).

10 Jongman, V., Lamoth, C.JC., Van, H., Caljouw, S.R.: Postural control of elderly: moving to predictable and unpredictable targets. Studies in health technology and informatics, 181: p. 93-97 (2012)

11 Nawaz, A., Skjaeret, N., Ystmark, K, Helbostad., JL, Vereijken, B, Svanaes, D.: Assessing Seniors' Perceived User Experience (UX) of Exergames for Balance Training. [DOI], To be presented in NordicCHI2014, (Helsinki, October, 26-30), (2014)

12 Cornejo, R., Hernández, D., Favela, J., Tentori, M., \& Ochoa, S. (2012, May). Persuading older adults to socialize and exercise through ambient games. InPervasive Computing Technologies for Healthcare (PervasiveHealth), 6th International Conference on (pp. 215218). IEEE, (2012)

13 Skjaeret, N., Nawaz, A., Ystmark, K, Dahl,Y., Helbostad., JL, Svanaes, D, and Vereijken, B. Designing for Movement Quality in Exergames: Lessons Learned from Observing Senior Citizens Playing Stepping Games. To appear in Gerontology (2014). DOI: $10.1159 / 000365755$

14 Proffitt, R. and B. Lange.: User Centered Design and Development of a Game for Exercise in Older Adults. International Journal of Technology, Knowledge \& Society. 8(5), (2012)

15 ISO 9241 . Ergonomics of Human-System Interaction-Part 210: Human-Centred Design for Interactive Systems, International Organization for Standardization (ISO), Geneva, Switzerland (2010).

16 Houde, S., \& Hill, C.: What do prototypes prototype. Handbook of human-computer interaction, 2, 367-381, (1997) 